\title{
Comparison of Hypoxanthine, Lactate, and ECG Signs as Indicators of Hypoxia
}

\author{
PETER E. TUCHSCHMID, ${ }^{(27)}$ URS BOUTELLIER, ERWIN A. KOLLER, AND GABRIEL V. DUC \\ Division of Neonatology, Department of Pediatrics and Institute of Physiology, University of Zurich, Zurich, \\ Switzerland
}

\begin{abstract}
Summary
High altitude-induced hypoxemia in 26 young adults was used to compare hypoxia parameters such as blood lactate, hypoxiainduced electrocardiogram signs, and the recently proposed plasma hypoxanthine concentration. At a $\mathrm{PaO}_{2}$ of $30 \mathrm{~mm} \mathrm{Hg}$, no elevation in hypoxanthine and small increase in lactate was observed. Minimal leg exercise was added to further increase hypoxia during hypoxemia. A significant increase in lactate and considerable ST-T depression in electrocardiogram indicated hypoxia, but no change in plasma hypoxanthine was found. Work-dependent hyperventilation as a main cause of lactate elevation was excluded. Blockade of hypoxanthine breakdown by allopurinol in vivo increased plasma hypoxanthine levels, but hypoxemia with or without leg exercise failed to consistently increase this level further. Elevations of blood lactate above the normal range were found at a $\mathrm{PaO}_{2}$ of $30 \mathrm{~mm} \mathrm{Hg}$ and below.
\end{abstract}

\section{Speculation}

The increased plasma hypoxanthine concentration in newborns after delivery may result from other factors, additional to hypoxia, because in mild hypoxemic hypoxia in healthy adults hypoxanthine was not elevated, although blood lactate was already increased. Cellular hypoxia is indicated by beginning of lactate elevation at a threshold level of $\mathrm{PaO}_{2}$ of $30 \mathrm{~mm} \mathrm{Hg}$.

Hypoxia has been recognized as the main cause of brain damage in the perinatal period. Because in clinical situations lack of cellular oxygen cannot be directly measured, indirect parameters to detect this condition have been studied. Three types of signals have been used in clinical perinatology: blood oxygen transport variables, cellular activity, and metabolic products.

Parameters of oxygen transport (arterial or transcutaneous $\mathrm{Po}_{2}$ and oxygen saturation) are useful if hypoxia is caused by hypoxemia (for definitions, see Ref. 4). They are unable to detect hypoxia due to reduced perfusion and cannot be used as markers of past hypoxia. Parameters of cellular activity which are clinically available such as variations in heart rate and respiratory patterns are accepted as screening parameters, but they are influenced by a number of other factors, and the interpretation of their variations is difficult. The relation of electroencephalogram to brain hypoxia is now beginning to be documented, but not yet introduced in routine (9).

Changes in metabolic products, particularly elevation of blood lactate, represent a useful signal of anaerobic glycolysis. Because blood lactate disappears quickly after correction of hypoxia and may also be elevated in the absence of hypoxia $(8,10,24)$, obstetricians and neonatologists are still in search of other indicators.

Hypoxanthine, a purine metabolite, was found to be elevated in severe hypoxic conditions in animal models $(21,22)$ and newborns (18), but no clear correlation between plasma hypoxanthine levels and severity of intrauterine hypoxia could be found (15). Because these situations cannot be considered to be pure hypoxia, we looked for a model of well-defined and isolated hypoxia in man. We studied the following parameters of hypoxia: hypoxanthine, lactate, and electrocardiogram (ECG) alterations in adults exposed to an altitude of $6000 \mathrm{~m}$ in a low-pressure chamber.

\section{MATERIALS AND METHODS}

\section{SUBJECTS}

Twenty-six young male adults were asked to participate in the experiment. Their state of health was checked by clinical examinations and ECG during exercise of $150 \mathrm{~W}$ or more. The informed consent of all participants was obtained.

\section{LOW-PRESSURE CHAMBER}

The system described in detail by Laciga and Koller (13) was used. The test person was supine for about $1 \mathrm{hr}$ before and during the experiment ( 2 to $3 \mathrm{hr}$ ) and was controlled by a physician present in the chamber. No experiment had to be terminated because of subjective inconvenience or deterioration as was noted at $7000 \mathrm{~m} \mathrm{(14).}$

\section{EXPERIMENTAL PROCEDURE}

A standardized procedure was followed, and major deviations are mentioned in "Results." Ascent and descent were carried out at a rate of $750 \mathrm{~m} / \mathrm{min}$ and were interrupted every $1000 \mathrm{~m}$ for 6 to $8 \mathrm{~min}$. The stay at maximal altitude, however, lasted 20 to 30 min. ECG and circulatory and respiratory parameters were registered at each altitude level and twice at $6000 \mathrm{~m}$. Blood samples were obtained from a cubital vein catheter which was placed before the beginning of the experiment. In nine experiments, the test person performed an exercise consisting of leg movements (20 watts, $4 \mathrm{~min}$ ) at ground level as well as at $6000 \mathrm{~m}$.

\section{RESPIRATION}

Respired air was analyzed during one min at each altitude level by a mass spectrometer (M-3, MAT; Varian). Alveolar $\mathrm{PaO}_{2}$ and $\mathrm{PaCO}_{2}$ were calculated from the corresponding endexpiratory values. Ventilation was recorded by a Fleisch-pneumotachograph.

\section{CIRCULATION AND ELECTROCARDIOGRAPHY}

Blood pressure was measured at each altitude level, and heart rate was followed continuously. The electrocardiogram was obtained as described elsewhere (13). Standard bipolar limb leads (Einthoven) and unipolar precordial leads (Wilson) were recorded; $V_{2}, V_{4}$, and $V_{6}$ were monitored as a control of the test person. ST$T$ changes were analyzed by dividing the segment in four equal intervals, yielding five regularly distributed points. Amplitudes of corresponding points were compared by paired $t$ tests and aver- 
aged to visualize changes of a group of probands during ascent to $6000 \mathrm{~m}$.

\section{BLOOD SAMPLING}

Blood was collected from the permanent vein catheter in a heparinized syringe. One part of the sample was used for blood gas measurements (AVL; Schaffhausen, Switzerland), the other was immediately deproteinized for lactate determination or centrifuged, and the plasma was frozen for hypoxanthine measurements.

\section{CHEMICAL ANALYSIS}

Lactate. Supernatants of the deproteinized duplicate blood samples ( 1 volume of blood in 2 volumes of ice-cold $0.6 \mathrm{M}$ perchloric acid) were obtained within $4 \mathrm{hr}$ after collection by centrifugation and were stored frozen at $-20^{\circ} \mathrm{C}$ until lactate was determined with a commercially available kit (Böhringer, Mannheim, West Germany).

Hypoxanthine. Two methods were used. During eight preliminary experiments, hypoxanthine was determined by the $\mathrm{PO}_{2}$ method introduced by Saugstad (19) with the following modifications shown to have no influence on the accuracy of the original technique. The micro-pO, $\mathrm{P}_{2}$ electrode (E 5021 a; Radiometer, Copenhagen, Denmark) was operated at $25^{\circ} \mathrm{C}$ rather than at $37^{\circ} \mathrm{C}$ and only one-half of catalase activity and only one-fifth of xanthine oxidase activity was used. Plasma samples stored at $-20^{\circ} \mathrm{C}$ for up to 2 wk were centrifuged $(8000 \times g$ for $30 \mathrm{sec})$ before the determination. Differences in $\mathrm{PO}_{2}$ before and after addition of xanthine oxidase were calculated from the recorded $\mathrm{Po}_{2}$ traces to correct for drifting baselines. The electrode was calibrated with water-saturated atmospheric air at a known barometric pressure. Calibration curves with standard hypoxanthine solutions were obtained daily.

The plasma concentration of hypoxanthine in the remaining 18 subjects was determined by a newly developed method. Figure 1 depicts the combination of hydrogen peroxide-producing oxidation of hypoxanthine with the detection of the former (6) by the enzyme aldehyde dehydrogenase (EC 1.2.1.5). An assay mixture containing $10 \%(\mathrm{w} / \mathrm{v})$ of ethanol, $13 \mathrm{IU} / \mathrm{ml}$ of catalase, $6 \mathrm{IU} / \mathrm{ml}$ of aldehyde dehydrogenase, $10 \mathrm{mM}$ of NADP, $50 \mathrm{mM}$ of sodium pyrophosphate and $50 \mathrm{mM}$ of potassium chloride, adjusted to a final $\mathrm{pH}$ of 7.4, was prepared daily and kept on ice. Eight-tenths $\mathrm{ml}$ of this assay mixture and $0.2 \mathrm{ml}$ of plasma (or $0.9 \%$ sodium chloride as blank or 5 to $50 \mu \mathrm{M}$ hypoxanthine standard solution) was placed in a $1 \mathrm{~cm}$ path cuvette. The absorbance at $340 \mathrm{~nm}$ was recorded in a spectrophotometer thermostated to $37^{\circ} \mathrm{C}$. After warming up, $5 \mu \mathrm{l}$ of xanthine oxidase solution $(4 \mathrm{IU} / \mathrm{ml}$ in $50 \mathrm{mM}$ sodium pyrophosphate, $50 \mathrm{mn}$ potassium chloride, $\mathrm{pH} 7.4$ ) were added, and the increase in the absorbance was followed to the end

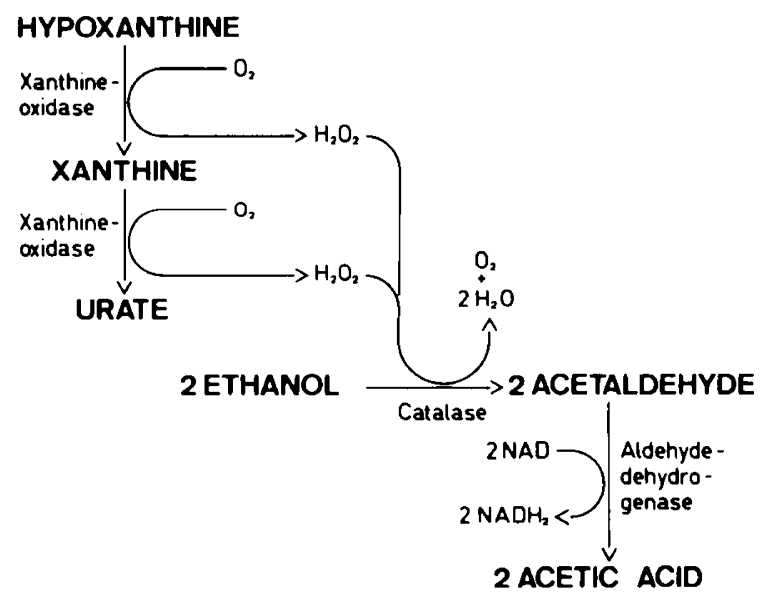

Fig. 1. Reaction pathway used for the modified determination of hypoxanthine (see "Materials and Methods"). point of the reaction (within $5 \mathrm{~min}$ ). Hypoxanthine concentration was calculated from the change in absorbance at $340 \mathrm{~nm}$, corrected for the blank reading, and read on a daily prepared calibration curve.

Chemicals. All reagents were of analytical grade. Xanthine oxidase (EC 1.2.3.2), $0.4 \mathrm{IU} / \mathrm{mg}$, and catalase (EC 1.11.1.6), 65,000 IU/mg, were obtained as crystal suspensions, and aldehyde dehydrogenase (EC 1.2.1.5), $15 \mathrm{IU} / \mathrm{mg}$, was obtained as lyophilized powder from Böhringer (Mannheim, West Germany). The crystallized enzymes were centrifuged, and the sediments were made up to the initial volume with the appropriate buffer before their use. Hypoxanthine was obtained from Merck (Darmstadt, West Germany), dissolved in $0.1 \mathrm{M}$ sodium-carbonate, and then adjusted to $\mathrm{pH} 8.0$ and used as standard stock solution for not longer than one day.

Statistical Analyses. Paired two-tailed $t$ test was used to determine the significance of the data obtained (17).

\section{RESULTS}

\section{COMPARISON OF THE TWO METHODS TO DETERMINE HYPOXANTHINE}

The detection limit of $\mathrm{PO}_{2}$ method (19) turned out to be 4 to 6 $\mu \mathrm{M}$ in hypoxanthine, corresponding to a change in $\mathrm{Po}_{2}$ of 3 to 4 $\mathrm{mm} \mathrm{Hg}$ of the initial $\mathrm{Po}_{2}$ of $145 \mathrm{~mm} \mathrm{Hg}$ (water-saturated room air at $25^{\circ} \mathrm{C}$ ). We were unable to detect changes of plasma hypoxanthine concentrations within the normal range of 0 to $5 \mu \mathrm{M}$ by this technique, which is suitable to determine rapidly and easily elevations above the normal range. With the aldehyde dehydrogenase method, the detection limit was less than $2 \mu \mathrm{M}$ of hypoxanthine, corresponding to a change in absorbance of $0.002(\Delta \mathrm{E})$.

The normal values for hypoxanthine determined by this method in plasma of adults were $3.2 \pm 2.5 \mu \mathrm{M}$; range, 0.4 to $9.9 \mu \mathrm{M}(n=$ 13 ) in agreement with the earlier reported values $(11,19)$ but slightly higher than those found by Kugler $(12)(1.3 \pm 1.0 \mu \mathrm{M})$ and by Remme et al. (16) $(1.2 \pm 0.2 \mu \mathrm{M})$.

\section{EFFECT OF HYPOXEMIA ON PLASMA LACTATE, HYPOXANTHINE. AND ECG}

Fifteen healthy volunteers exposed to an altitude of $6000 \mathrm{~m}$ during $27 \pm 3 \mathrm{~min}$ showed a decrease in $\mathrm{PaO}_{2}$ from $94.5 \pm 3.3 \mathrm{~mm}$ $\mathrm{Hg}$ at ground level to $30.9 \pm 2.9 \mathrm{~mm} \mathrm{Hg}$. No change of plasma hypoxanthine was observed in seven subjects where it was determined by the Po.2 technique. Figure 2 summarizes the findings in the further eight experiments. No increase in plasma hypoxanthine, determined by the aldehyde dehydrogenase method could be observed throughout the experiments. Blood lactate was not elevated at the time of minimal $\mathrm{Po}_{2}$ but some 10 to 20 min later during descent $(4000 \mathrm{~m})$ when compared to the initial value at $450 \mathrm{~m}(P<0.05)$. No elevation above the normal range of 1.11 to $1.33 \mathrm{mM}(5)$ was detectable. The ST-T segments of the ECG of both groups of the above mentioned experiments $(n=15)$ at ground level were compared with those at $6000 \mathrm{~m}$. The S-T segment was significantly depressed $(P<0.01)$ in the left precordial leads (Fig. 3, $V_{5}$ ), in contrast to the right precordial leads (Fig. $3, V_{2}$ ). The voltage of the $T$-wave was decreased in all leads, the flattening, however being more pronounced in $V_{5}(P<0.001)$ than in $\mathrm{V}_{2}(P<0.01)$. The $\mathrm{Q}-\mathrm{T}$ interval was shortened in absolute terms at $6000 \mathrm{~m}$, but relatively prolonged with regard to the increased heart rate.

\section{EFFECT OF EXERCISE AND HYPOXEMIA ON PLASMA HYPOXANTHINE AND LACTATE}

Influence of minimal work load on hypoxia parameters was studied in five experiments. Figure 4 shows the absence of a hypoxanthine elevation due to work at both altitudes, whereas lactate increases significantly at $6000 \mathrm{~m}(P<0.05)$ but not at 450 $m$ after work. Table 1 summarizes the changes due to exercise at both altitudes and includes respiratory data inasmuch as they are 


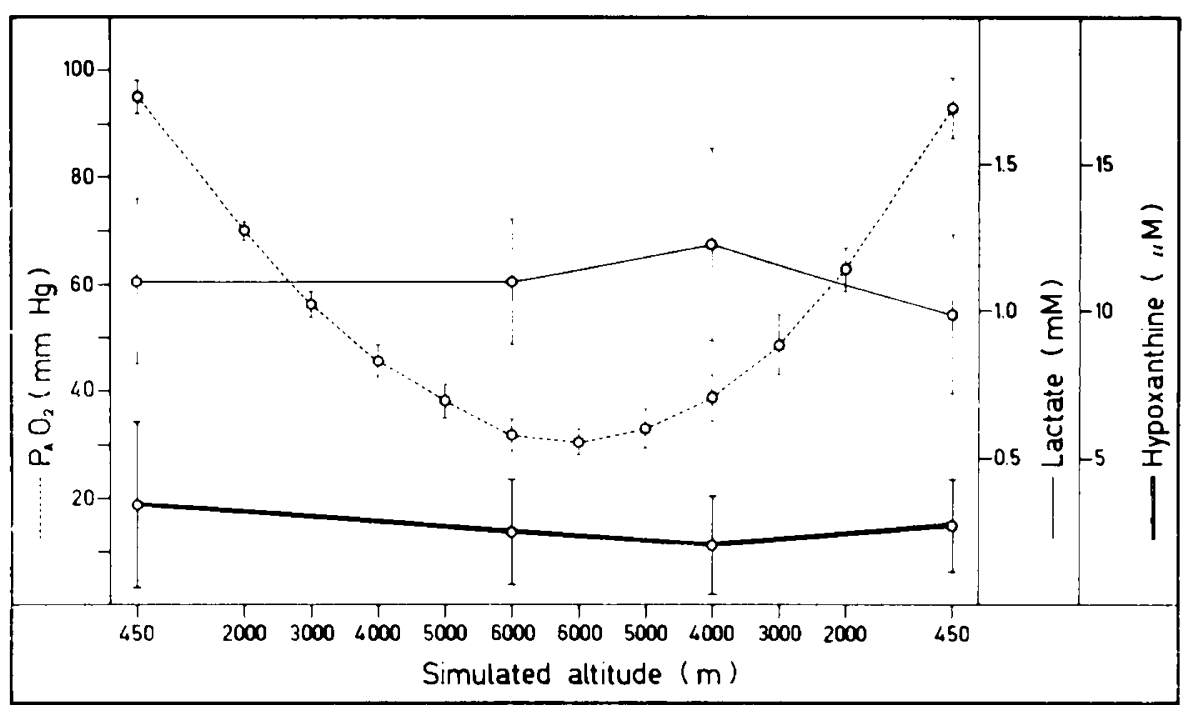

Fig. 2. Pao.: $(---)$, blood lactate $(-)$, and plasma hypoxanthine $(-)$ (mean values \pm I S.D.) during exposure of eight healthy adults to reduced atmospheric pressure.

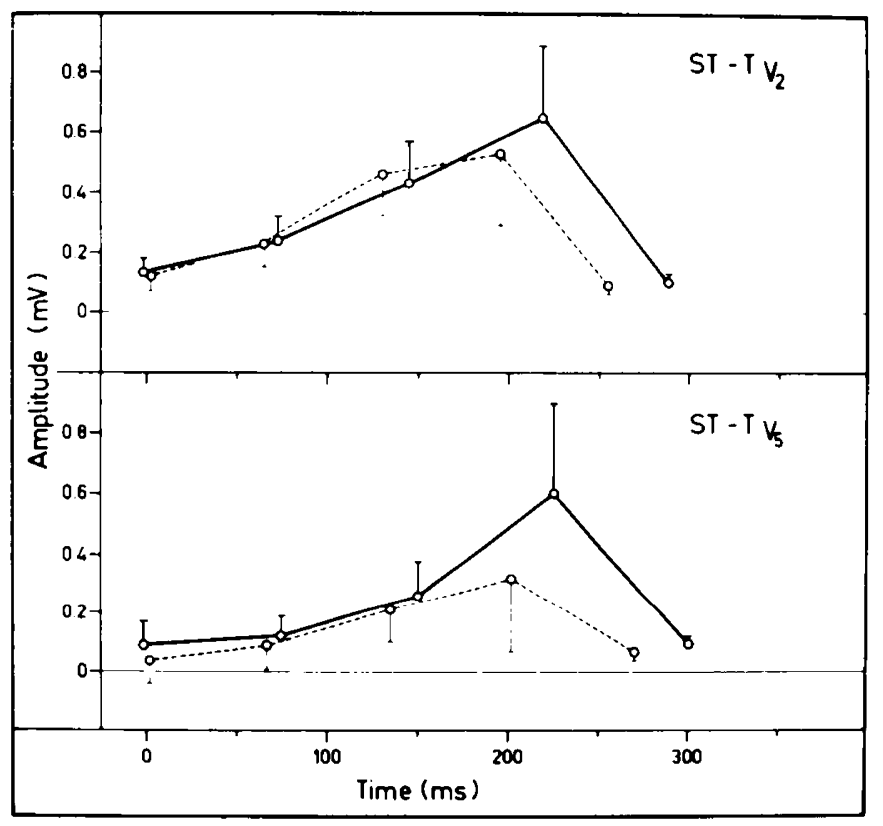

Fig. 3. Comparison of ST-T segments of ECG leads $V_{2}$ and $V_{5}$ at ground level (mean +1 S.D.) $(-)$ and at $6000 \mathrm{~m}$ (mean, - I S.D.) (- - -) of 15 healthy adults exposed to reduced atmospheric pressure.

essential in the interpretation of lactate concentration because alkalosis can cause an elevation of lactate (24). In one case, given separately in Table 1 and excluded from Figure 4, marked hyperventilation (see $\dot{\mathrm{V}}, \mathrm{PaCO}_{2}, \mathrm{pH}$ ) occurred during exercise resulting in excessive increase in lactate. In the other cases, a further increase in ventilation was excluded considering $\mathrm{pH}$ and $\mathrm{PaCO}_{2}$. Heart rates increased significantly $(P<0.001)$ during ascent to $6000 \mathrm{~m}$, and blood pressure showed only small decrease of the diastolic values.

EFFECT OF EXERCISE AND HYPOXEMIA ON PLASMA HYPOXANTHINE AND LACTATE AFTER IN VIVO INHIBITION OF HYPOXANTHINE BREAKDOWN

To distinguish hypoxanthine production from its steady state concentration in the plasma, the purine breakdown was inhibited at the enzymatic conversion of hypoxanthine to xanthine and to urate by the xanthine oxidase inhibitor allopurinol. Thus the subjects were given $3 \times 100 \mathrm{mg}$ Zyloric (Wellcome) during 3 days preceeding the exposure to high altitude. This caused a significant elevation $(P<0.001)$ of plasma hypoxanthine from $3.2 \pm 2.5 \mu \mathrm{M}$ $(n=13)$ to $10.9 \pm 4.9 \mu \mathrm{M}(n=6)$. Figure 5 demonstrates that leg exercise as stated in the preceeding paragraph causes no change in plasma hypoxanthine at either altitude, whereas lactate is consistently elevated by work at $6000 \mathrm{~m}$ but not at ground level. Table 2 summarizes the work-induced changes including blood gas values. Data on $\mathrm{PaCO}_{2}$ changes and respiratory minute volumes exclude an augmented ventilation caused by exercise in these experiments. A significant increase in heart rates $(P<0.05)$ and only minimal changes of blood pressure were noted during ascent to $6000 \mathrm{~m}$. To rule out inhibitory effects of plasma of allopurinoltreated persons on xanthine oxidase used to quantitate hypoxanthine, the recovery of an added hypoxanthine standard was checked. In Figure 6, lactate concentrations of six experiments with exercise were plotted against the corresponding $\mathrm{PaO}_{2}$ and mean lactate values were calculated in $\mathrm{PaO}_{2}$ groups of $10 \mathrm{~mm} \mathrm{Hg}$. The significance of the changes in mean lactate were tested against the mean lactate in the group of $\mathrm{PaO}_{2}$ of 90 to $100 \mathrm{~mm} \mathrm{Hg}$ using the $t$ test for small samples with unequal variance (17).

\section{DISCUSSION}

No clinical parameter to detect past hypoxia is available at present. Only concomitant or very recent hypoxic events can be detected by heart rate monitoring during delivery (7) or by blood lactate measurement (3). An extension of the lag between time of hypoxia and moment of its detection as well as a more sensitive factor would be of interest for perinatologists concerned with the problem of intrauterine hypoxia. Reports that plasma concentration of the purine metabolite hypoxanthine depends on the oxygen supply to tissue in animal models (21) as well as in newborns (18) were of special interest because it might be the factor looked for. The sensitivity in detecting hypoxia of this newly found parameter is compared in this study with the classical ones. like increase in blood lactate and depression of the ST-T segment of the ECG. Because QT changes depend on heart-rate, their interpretation is more difficult than those of ST-T changes, and only the latter are further analyzed. Because of the complexity of changes in metabolism, respiration, and circulation at birth, newborns are not good models of pure hypoxemic hypoxia, particularly because cellular breakdown in ischemia and severe acidosis are a source of purine metabolites independent of hypoxia $(2,25)$ (see Fig. 7). We considered that hypoxemia in healthy adults provides a better condition for differentiating between hypoxemic hypoxia and other situations possibly increasing production of hypoxanthine in man. 


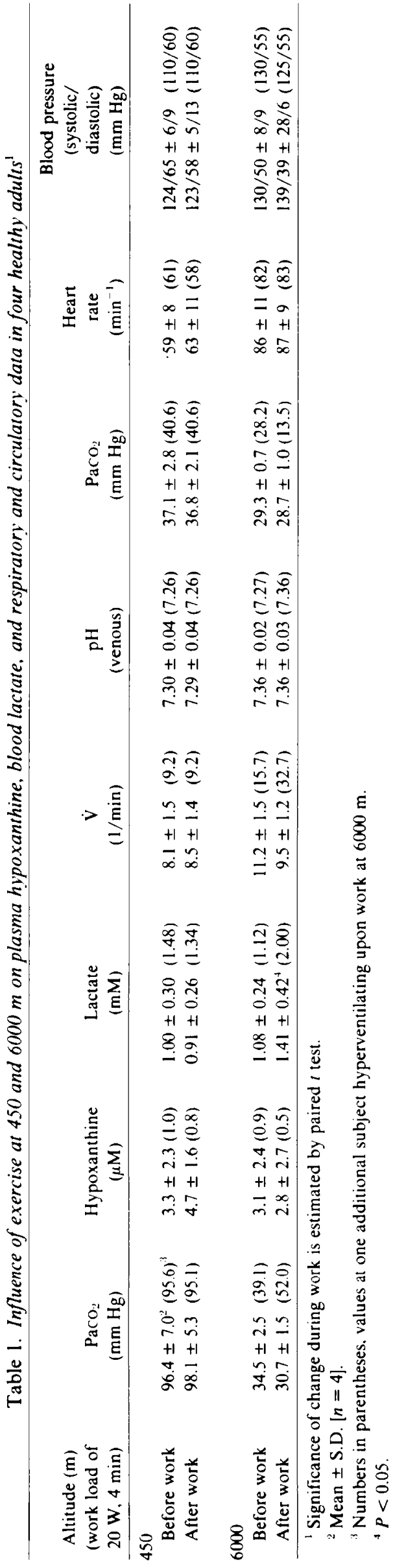

In the experiments reported here, mean minimal $\mathrm{PaO}_{2}$ of 30.9 $\mathrm{mm} \mathrm{Hg}$ can be considered as mild hypoxia (23), but it should be pointed out that further decrease in $\mathrm{PaO}_{2}$ leads to signs of serious deterioration as unconsciousness, ectopic heart beats, or cardiac arrest (14). With the exception of two occasions, no elevation of plasma hypoxanthine was found in the 26 reported experiments.

In two cases, hypoxanthine increased upon work at $6000 \mathrm{~m}$ in individuals with allopurinol-blocked hypoxanthine breakdown, but the same effect was missing in the other two subjects of the same experimental group. Lack of increase of hypoxanthine during exposition to hypoxemia could have the following reasons: (1) insensitivity of the detection of hypoxanthine; (2) insufficient hypoxia; and (3) prevention of accumulation of hypoxanthine by too rapid degradation in vivo.

(1) Normal values of hypoxanthine are near the detection limit of the $\mathrm{PO}_{2}$ method (see "Materials and Methods"), and changes not exceeding the normal range can not be ruled out. Two- to three-fold increase in sensitivity was achieved by the newly developed method, and no differences between the normal values obtained with the two alternative methods were observed. Even with increased sensitivity, no elevation of hypoxanthine levels was noted during hypoxemia. Inasmuch as only elevations larger than the considerable variations of the normal values are of diagnostic interest, a further increase in sensitivity of the hypoxanthine detection would be of limited value.

(2) To test whether the experimental hypoxemia led to hypoxia, two classical parameters, increase in lactate and depression of ST$T$ segment of the ECG, were concomitantly analyzed. Small but significant changes of lactate concentration and considerable hypoxia-induced ECG changes particularly in the left precordial leads indicated the presence of hypoxia. In experiments with additional slight work, hypoxanthine remained unchanged although a further increase in lactate occurred. This additional work did not cause changes either in lactate or in the ECG at normal altitude. No lactate/pyruvate ratios were measured to exclude that hyperventilation was the cause of rise in lactate during work. The statistically significant increase in blood-pH during work at 6000 m (Table 2) is too small to be of biologic relevance and is contrasted by unchanged $\mathrm{PaCO}_{2}$ and $\dot{\mathrm{V}}$, thus strongly suggesting that augmentation of lactate was independent of hyperventilation. Duration of maximal hypoxemia was in the order of $30 \mathrm{~min}$. Separate analyses of two experiments with a prolonged stay $(60$ $\mathrm{min}$ ) at $6000 \mathrm{~m}$ showed no difference to the normal experiments in respect to hypoxanthine concentrations. Conclusion drawn from these data are therefore limited to mild, acute hypoxia. Similarly, Kugler (12) did not find significant elevations of coronary sinus hypoxanthine concentrations, but did find considerable elevations of inosine and lactate during pacing-induced angina pectoris. Remme et al. (16) found in analogous pacing experiments small but significant elevations of coronary sinus hypoxanthine, but none in the arterial blood, indicating that hypoxanthine release of the ischemic heart muscle is too small to be detected systemically. It was further shown that lactate occurred earlier in gradual pacing, which supports our findings.

(3) Increased production of hypoxanthine may remain undetected if its degradation is rapid enough to prevent its accumulation in spite of increased production. Among the breakdown products of ADP (Figure 7), hypoxanthine can be considered as a good parameter of hypoxia because the xanthine oxidase reaction is oxygen dependent. If, on the other hand, the latter reaction is less sensitive to hypoxia than the degradation of ATP, elevation of hypoxanthine would be less than expected or even absent. Blockade of the enzyme xanthine oxidase in vivo would therefore increase the sensitivity of the plasma hypoxanthine concentration as a hypoxia parameter. Pharmacologic inhibition of the enzyme by allopurinol increased hypoxanthine levels in the absence of hypoxia, confirming its predicted action in vivo. No elevation of hypoxanthine levels caused by hypoxia was observed in four experiments with allopurinol blockade, whereas changes were consistently found for lactate and ECG parameters. No conclu- 


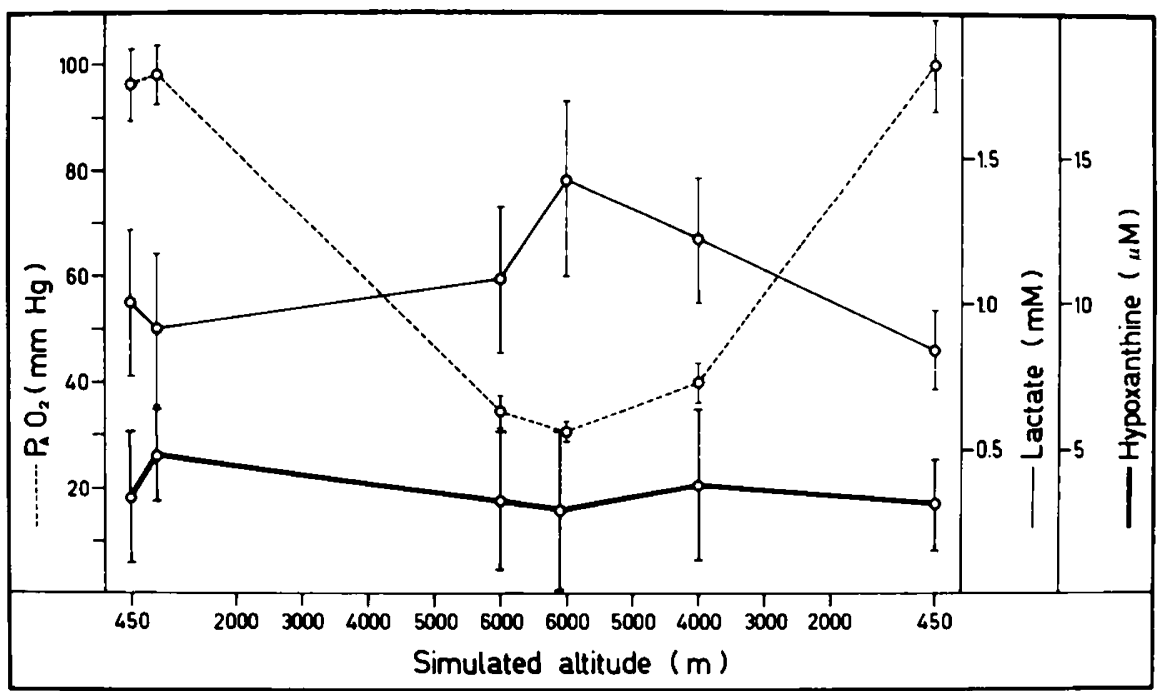

Fig. 4. $\mathrm{PaO}_{2}(----)$, blood lactate (-), and plasma hypoxanthine $(-)$ (mean values \pm I S.D.) during hypoxemia and exercise (20 W during 4 min: shaded areas) in four healthy adults exposed to reduced atmospheric pressure.

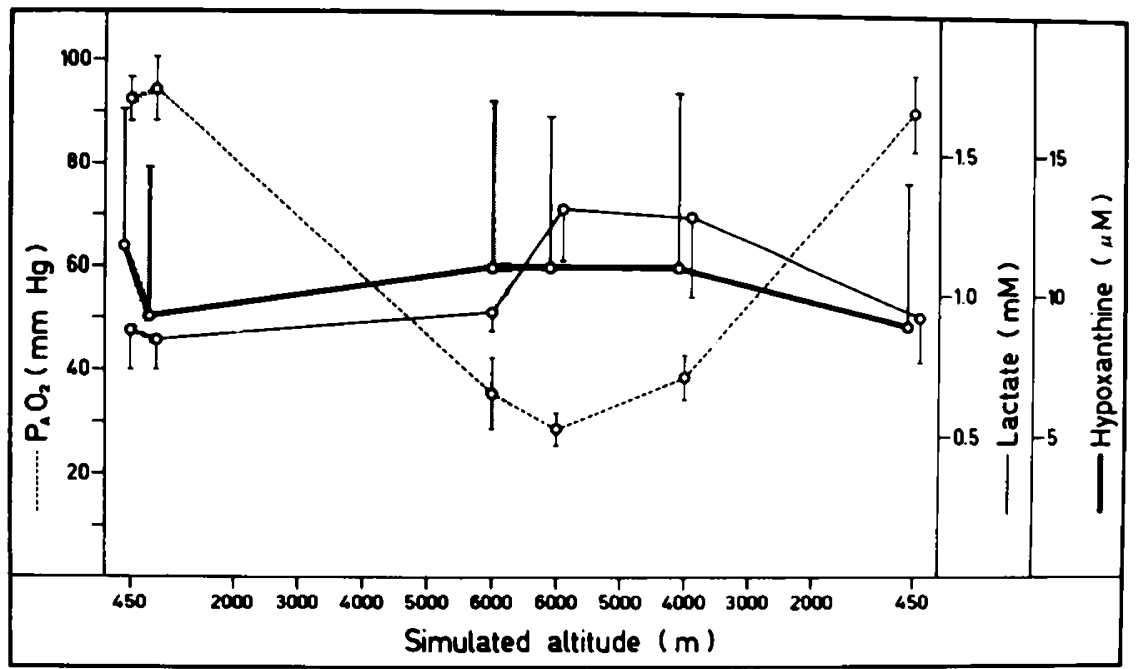

Fig. 5. $\mathrm{PaO}_{2}(---)$, (mean values \pm I S.D.), blood lactate (-), (mean values, -1 S.D.) and plasma hypoxanthine ( $\longrightarrow$ ) (mean values +1 S.D.) during hypoxemia and exercise ( $20 \mathrm{~W}$ during $4 \mathrm{~min}$ : shaded areas) in four healthy adults with allopurinol-blocked hypoxanthine breakdown exposed to reduced atmospheric pressure.

Table 2. Influence of exercise at 450 and at $6000 \mathrm{~m}$ on plasma hypoxanthine, blood lactate, and respiratory and circulatory data in four healthy adults with allopurinol-blocked hypoxanthine breakdown ${ }^{1}$

\begin{tabular}{|c|c|c|c|c|c|c|c|c|}
\hline $\begin{array}{l}\text { Altitude (m) } \\
\text { (work load of } \\
20 \mathrm{~W}, 4 \mathrm{~min} \text { ) }\end{array}$ & $\begin{array}{c}\mathrm{PaCO}_{2} \\
(\mathrm{~mm} \mathrm{Hg})\end{array}$ & $\begin{array}{c}\text { Hypo- } \\
\text { xanthine } \\
(\mu \mathrm{M})\end{array}$ & $\begin{array}{l}\text { Lactate } \\
(\mathrm{mM})\end{array}$ & $\begin{array}{c}\dot{\mathrm{V}} \\
(1 / \mathrm{min})\end{array}$ & $\begin{array}{c}\mathrm{pH} \\
\text { (venous) }\end{array}$ & $\begin{array}{c}\mathrm{PaO}_{2} \\
(\mathrm{~mm} \mathrm{Hg})\end{array}$ & $\begin{array}{c}\text { Heart } \\
\text { rate } \\
\left(\min ^{-1}\right)\end{array}$ & $\begin{array}{c}\text { Blood pressure } \\
\text { (systolic/ } \\
\text { diastolic) } \\
\text { (mm Hg) }\end{array}$ \\
\hline \multicolumn{9}{|l|}{450} \\
\hline Before work & $92.5 \pm 4.7^{2}$ & $11.7 \pm 4.9$ & $0.87 \pm 0.14$ & $6.8 \pm 0.9$ & $7.30 \pm 0.05$ & $37.1 \pm 1.9$ & $62 \pm 7$ & $121 / 59 \pm 9 / 3$ \\
\hline After work & $94.5 \pm 5.9$ & $9.2 \pm 5.4$ & $0.83 \pm 0.10$ & $7.0 \pm 1.2$ & $7.29 \pm 0.04$ & $37.6 \pm 2.1$ & $60 \pm 7^{3}$ & $116 / 56 \pm 8 / 3$ \\
\hline \multicolumn{9}{|l|}{6000} \\
\hline Before work & $35.8 \pm 7.0$ & $11.0 \pm 5.9$ & $0.92 \pm 0.07$ & $11.4 \pm 3.4$ & $7.36 \pm 0.07$ & $26.7 \pm 4.9$ & $81 \pm 18$ & $116 / 61 \pm 21 / 9$ \\
\hline After work & $28.8 \pm 3.3$ & $11.0 \pm 5.6$ & $1.29 \pm 0.21^{3}$ & $10.5 \pm 1.7$ & $7.38 \pm 0.07^{4}$ & $26.0 \pm 3.4$ & $80 \pm 8$ & $120 / 46 \pm 7 / 10$ \\
\hline
\end{tabular}

\footnotetext{
${ }^{1}$ Significance of change during work is estimated by paired $t$ test.

${ }^{2}$ Mean \pm S.D. $(n=4)$.

${ }^{3} P<0.05$.

${ }^{4} P<0.01$.
}

sions concerning half-life of hypoxanthine can be made from our data, but differences in arteriovenous concentrations of the metabolite in dogs (21) suggest that its rapid breakdown is possibly caused by xanthine oxidase activity. Even in pigs which possess no xanthine oxidase in their lung tissue (1), the half-life of hypoxanthine was found to be $\mathbf{4 0} \mathrm{min}$ and, in the same experiment. less than the half-life of the lactate elevation (20). The presence of a measurable arteriovenous difference of hypoxanthine concentra- 


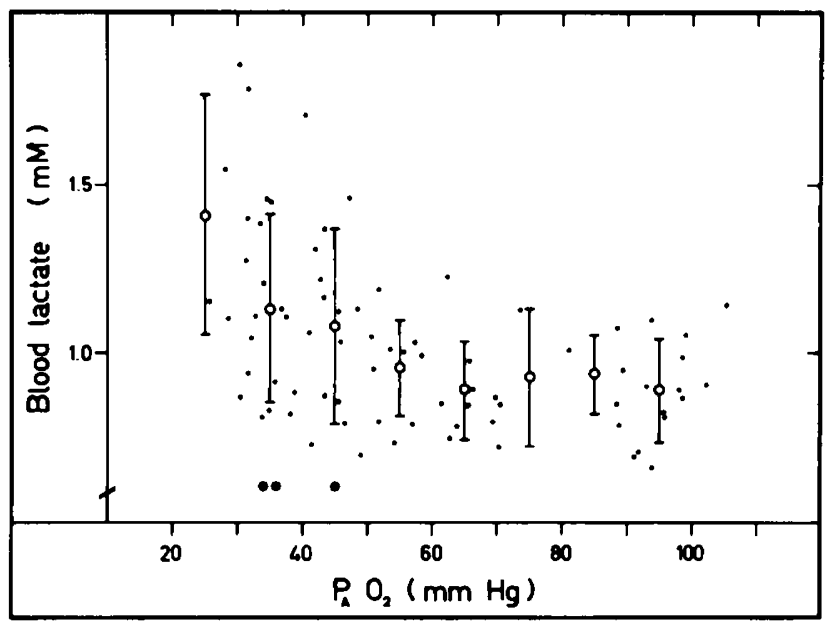

Fig. 6. Correlation of blood lactate concentrations with $\mathrm{PaO}_{2}$ in healthy adults exposed to reduced atmospheric pressure. Mean lactate concentrations ( \pm I S.D.) were calculated in $\mathrm{PaO}_{2}$ groups of $10 \mathrm{~mm} \mathrm{Hg.}{ }^{*}, P<0.05$; **, $P<0.01$ as compared to the 90 to $100 \mathrm{~mm} \mathrm{Hg}$ mean value.

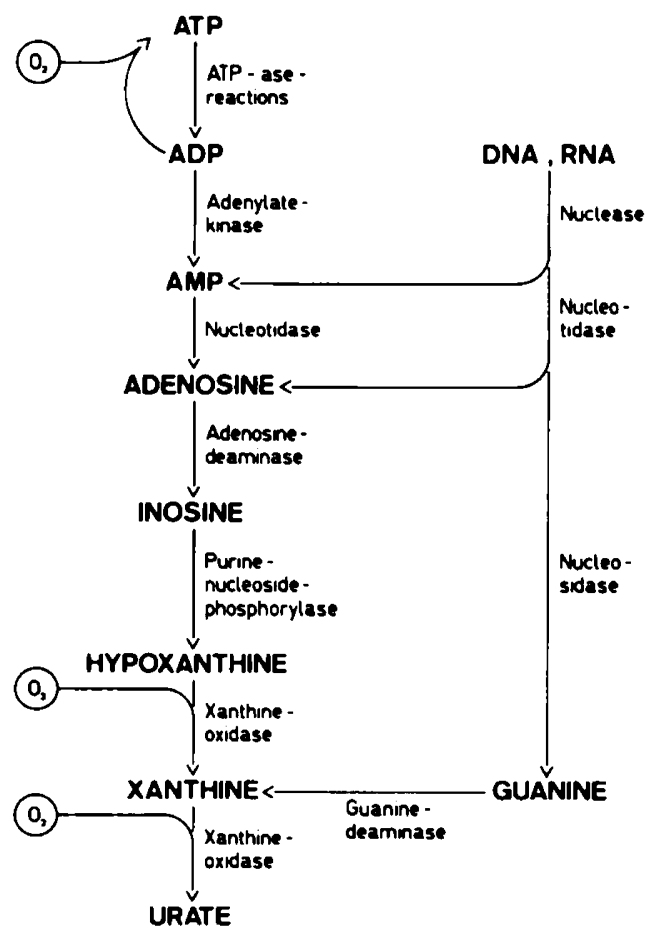

Fig. 7. Schematical pathway of purine catabolism including breakdown of nucleic acids.

tion in human cord blood (15) indicates its rapid clearance from the fetal circulation.

Plasma lactate concentrations in our experiments indicated the beginning of hypoxia. Figure 6 correlates $\mathrm{PaO}_{2}$ with corresponding lactate levels. Beginning lack of cellular oxygen is signaled by this parameter in the range of 50 to $40 \mathrm{~mm} \mathrm{Hg}$. Lack of significance of lactate elevation in the group of 20 to $30 \mathrm{~mm} \mathrm{Hg}$ is due to small number of measurements $(n=4)$. No comparable increase of hypoxanthine with decreasing $\mathrm{PaO}_{2}$ was noted.
From our experiments, we conclude that hypoxanthine in isolated, acute hypoxemic hypoxia in young adults is a less sensitive parameter than lactate and ST and $T$ changes of the ECG. Elevations of hypoxanthine in newborns as reported by Saugstad (18) and confirmed later (15) may be in part due to hypoxia but are probably influenced by other factors, like acidosis or cellular destruction, leading to an increase in purine breakdown.

\section{REFERENCES AND NOTES}

1. Al Khalidi, U. A. S., and Chaglassian, T. H.: The species distribution of xanthine oxidase. Biochem. J., 97: 318 (1965).

2. Berne, R. M., Rubio, R., and Curnish, R. R.: Release of adenosine from ischemic brain. Circ. Res., 35: 262 (1974).

3. Bratteby, L., and Swanström, S.: Arterial lactate and pyruvate concentration in the normal and asphyxiated newborn infant. Lactate in acute conditions. International Symposion, Basel, pp. 56-68 (S. Karger, Basel, 1979).

4. Duc, G.: Assessment of hypoxia in the newborn. Pediatrics, 48: 469 (1971).

5. Fenn, W. O., and Rahn. H.: Respiration. Handbook of Physiology. Vol. 2 p. 948 (American Physiological Society, Washington, D. C., 1965).

6. Haeckel, $\mathrm{R}$.: The use of aldehyde-dehydrogenase to determine $\mathrm{H}_{2} \mathrm{O}_{2}$-producing reactions. J. Clin. Chem. Clin. Biochem., 14: 101 (1976).

7. Hammacher, K., Huter, K. A., Bockelmann, J., and Werners, P. H.: Foetal heart frequency and perinatal condition of the foetus and newborn. Gynecologia, 166: 349 (1968).

8. Hermansen, L., and Stensvold, I.: Production and removal of lactate during exercise in man. Acta Physiol. Scand., 86: 191 (1972).

9. Hrbek, A., Karlberg, P., Kjellmer, I., Olsson, T., and Riha, M.: Clinical application of evoked electroencephalographic response in the newborn infants. Dev. Med. Child. Neurol., 19: 34 (1977).

10. Huckabee, W. E.: Relationship of pyruvate and lactate during anaerobic metabolism. J. Clin. Invest., 37: 255 (1958).

11. Klinenberg, J. R., Goldfinger, S., Bradley, K. H., and Seegmiller, J. E.: An enzymatic spectrophotometric method for the determination of xanthine and hypoxanthine. Clin. Chem., 13: 834 (1967).

12. Kugler, G.: Myocardial release of inosine, hypoxanthine and lactate during pacing-induced angina in humans with coronary antery disease. Eur. J. Cardiol., 9: 227 (1979).

13. Laciga, P., and Koller. E. A.: Respiratory, circulatory and ECG changes during acute exposure to high altitude. J. Appl. Physiol., 41: 159 (1976).

14. Laciga, P., and Koller, E. A.: Respiratory, circulatory and ECG-changes at 6000 $\mathrm{m}$ and $7000 \mathrm{~m}$. Experientia. 34: 900 (1978).

15. Lipp, A., Tuchschmid, P., Silberschmidt, M., and Duc, G.: Arterial cord blood hypoxanthine and intrauterine hypoxia. p. 24 Proc. Fifth Eur. Congr. Perinat. Med., Uppsala, Sweden (1976).

16. Remme, W. J., de Jong, J. W., and Verdouw, P. D.: Effects of pacing-induced myocardial ischemia on hypoxanthine efflux from the human heart. Am. J. Cardiol., 40: 55 (1977).

17. Sachs, L. Angewandte Statistik, p. 109 ff (Springer, Berlin, 1974).

18. Saugstad, $O$. D.: Hypoxanthine as a measurement of hypoxia. Pediatr. Res., 9: 158 (1975).

19. Saugstad, O. D.: The determination of hypoxanthine and xanthine with a $\mathrm{pO}_{2-}$ electrode. Pediatr. Res., 9: 575 (1975).

20. Saugstad, O. D., Aasen. A. O., and Hetland, Ø.: Plasma hypoxanthine levels in pigs during acute hypoxemia. Eur. Surg. Res.. 10:314 (1978).

21. Saugstad, O. D., Bø. G., Østrem, T., and Aasen, A. O.: Hypoxanthine levels of plasma during hypoxemia in dogs. Eur. Surg. Res., 9: 23 (1977).

22. Saugstad, O. D., Kroese, A., Myhre, H. O., and Andersen, R.: Alteration of plasma hypoxanthine concentration during ischemia in the forelimb of the pig. Scand. J. Clin. Lab. Invest., 37: 517 (1977).

23. Simmons, D. H., Alpas, A. P., Tashkin, D. P., and Coulson, A.: Hyperlactatemia due to arterial hypoxemia or reduced cardiac output, or both. J. Appl. Physiol., 45: 195 (1978)

24. Takano, N.: Role of hypocapnia in the blood lactate accumulation during acute hypoxia. Respir. Physiol., 4: 32 (1968).

25. Winn, H. R., Rubio, R., and Berne, R. M.: Brain adenosine production in the rat during 60 seconds of ischemia. Circ. Res., 45: 486 (1979).

26. The authors thank Drs. R. Nassehi and R. Stürm for medical surveillance of the test persons and $M$. Silberschmidt and $E$. Vögeli for their technical assistance.

27. Requests for reprints should be addressed to: Dr. P. Tuchschmid. Kinderspital, CH-8032 Zürich, Switzerland.

28. This research was supported in part by the Hartmann Müller Foundation. University of Zurich.

29. Received for publication January 14, 1980.

30. Accepted for publication May 27, 1980. 